\title{
IMPLANTATION OF THE RAT EMBRYO: FURTHER HISTOCHEMICAL OBSERVATIONS ON CARBOHYDRATE, RNA, AND LIPID METABOLIC PATHWAYS
}

\author{
GEORGE A. CHRISTIE* \\ Anatomy Department, University of Glasgow \\ (Received 19th May 1966, revised 21st July 1966)
}

Summary. The routes of metabolism of carbohydrate, lipid and RNA in relation to the implanting rat embryo are examined histochemically, using the standard dehydrogenase technique and, as substrates, $\alpha$ glycero-phosphate, $\beta$-hydroxy-butyrate, glucose-6-phosphate, 6-phospho-gluconate, lactate, isocitrate, succinate, malate (with both NAD and NADP as co-factors), alcohol (ethanol), furfuryl alcohol and glutamate. Lipid (Sudan III) and RNA (chrome-alum-gallocyanin with RNAse controls) were also investigated.

The results divide the enzymes into four groups:

(1) $\alpha$-glycerophosphate dehydrogenase and $\beta$-hydroxy-butyrate dehydrogenase, which are found mainly in the uterine epithelium where they accumulate just before its breakdown and then disappear, and which correspond well to the lipid distribution.

(2) glucose-6-phosphate dehydrogenase and 6-phosphogluconate dehydrogenase, whose distribution corresponds well with that of RNA suggesting that ribose production for RNA may be via the pentose shunt in this site. These enzymes are found in the primary decidua initially, and then mainly in the mesometrial stroma.

(3) Lactate, isocitrate, succinate and malate dehydrogenases which accumulate chiefly in the antimesometrial decidua up to 8 to $8 \frac{1}{2}$ days thereafter falling off in concentration, and whose distribution suggests that they may represent the route of glycogen breakdown in this site for energy production.

(4) alcoholdehydrogenase (function unknown), furfuryl dehydrogenase whose distribution suggests that it may be concerned with RNA turnover, and glutamate dehydrogenase, which is found in sites probably engaged in rapid protein turnover.

A lesser degree of staining of isocitric dehydrogenase as compared to other Krebs' cycle enzymes is demonstrated, and it is suggested that this is due to an associated decrease in NADPH diaphorase, which

* Present address: Department of Anatomy, Queen's College, Dundee. 
decrease may suggest transhydrogenation and associated stimulation of protein synthesis.

The function of the yolk-sac placenta is examined, and a possible route of protein absorption, breakdown to simpler substances, and re-secretion into the yolk-sac cavity for direct access to the embryo is suggested.

Finally the function of the decidua in relation to the nutrition of the embryo is examined and it is suggested that at least one of these functions may be the synthesis and transport to the embryo of protein for tissue growth.

\section{INTRODUCTION}

Mossman (1937) states that 'the decidua develops as a glycogen-storing tissue in some animals ... for the purpose of being invaded and absorbed by the trophoblast', thus suggesting that one of its main functions is that of nutrition of the growing embryo. In the rat, as was shown in a previous paper (Christie, 1966), an unusual situation exists in that two separate areas of decidua can be considered-one antimesometrial, in which glycogen accumulates until $6 \frac{1}{2}$ to 7 days, and then disappears again; and one mesometrial, in which a gradual accumulation, beginning at $7 \frac{1}{2}$ days and continuing thereafter, occurs. The antimesometrial region will form the decidua capsularis and eventually degenerate, while the mesometrial region forms the decidua basalis. Thus, one may examine the histochemistry of glycogen metabolism in one situation where rapid turnover is occurring and another immediately adjacent, in which gradual storage is taking place. Many of the steps in carbohydrate, lipid and RNA metabolism can be demonstrated histochemically, and it was decided to investigate the metabolic pathways followed by carbohydrate during the process of implantation in the rat. Some observations pertinent to the problem of the function of the decidua and the part played by it in the histiotrophic nutrition of the embryo are also presented.

\section{MATERIAL AND METHODS}

Virgin Wistar albino rats were used. Details of mating, timing of pregnancy and localization of early implantations are as in a previous communication (Christie, 1966). Rats were killed at $4 \frac{1}{2}, 5 \frac{1}{2}, 6 \frac{1}{2}, 7,7 \frac{1}{2}, 8,8 \frac{1}{2}, 9 \frac{1}{2}$ and $10 \frac{1}{2}$ days of pregnancy by cervical dislocation, and the uteri removed and frozen on solid carbon dioxide. Frozen sections were cut at $14 \mu$ on a cryostat, and incubated for various dehydrogenases as listed in Table 1. The incubation medium contained substrate, NAD or NADP, buffer (phosphate except for G-6-PDH, and 6-PGDH-tris-HCl), Nitro-BT, sodium cyanide and polyvinyl pyrrolidone. Control sections were incubated without substrate. NADH and NADPH diaphorases were also stained. Lipid was coloured on frozen sections with Sudan III or Sudan Black B in propylene glycol, and RNA was identified on paraffin sections of AFA-fixed material with chrome alum gallo-cyanine at $\mathrm{pH} 1.64$ using ribonuclease controls. 
Intensity of staining was assessed visually and arbitrarily coded as trace $(\mathrm{Tr}$ ) to $4+$. Sections were incubated singly, or (for comparison between stages) together in one lot of medium.

\section{RESULTS}

\section{NON-EMBRYONIC TISSUES}

The enzyme localizations observed divided the enzymes into four groups:

(1) Concerned with lipid metabolism- $\alpha \mathrm{GPDH}$ and $\beta \mathrm{OHDH}-$ whose localization corresponded well with that of the lipid.

(2) Concerned with ribose production (possibly for RNA synthesis) - G-6PDH and 6-PGDH-whose distribution corresponded well to that of RNA.

(3) Concerned with glycolysis-LDH, IDH, SDH, MDH-or with reversal of glycolysis- $\mathrm{ME}$ - whose distributions have relationships to the glycogen concentration which were constant for the group, but varied depending on the area under examination.

TABLE 1

\begin{tabular}{|c|c|c|}
\hline Enzyme & Reaction catalysed & Co-factor \\
\hline $\begin{array}{l}\alpha \text {-Glycerophosphate dehydrogenase } \\
(\alpha G P D H)\end{array}$ & $\begin{array}{l}\alpha \text {-Glycerophosphate } \leftrightarrow \text { dihydroxy- } \\
\text { acetone phosphate }\end{array}$ & NAD \\
\hline $\begin{array}{l}\beta \text {-Hydroxy-butyric dehydrogenase } \\
(\beta \text { OнDH })\end{array}$ & $\beta$-hydroxy-butyrate $\leftrightarrow$ aceto-acetate & NAD \\
\hline Lactic dehydrogenase (LDH) & Lactate $\leftrightarrow$ pyruvate & NAD \\
\hline Iso-citric dehydrogenase (IDH) & Iso-citrate $\leftrightarrow \alpha$-ketoglutarate & NADP \\
\hline Succinic dehydrogenase (SDH) & Succinate $\leftrightarrow$ fumarate & FAD \\
\hline Malic dehydrogenase (MDH) & Malate $\leftrightarrow$ oxalo-acetate & NAD \\
\hline 'Malic enzyme' (ME) & Malate $\rightarrow$ pyruvate & NADP \\
\hline Glutamic dehydrogenase (GDH) & Glutamate $\leftrightarrow \alpha$-ketoglutarate & NAD \\
\hline Alcohol dehydrogenase (ADH) & Ethanol $\leftrightarrow$ acetaldehyde & NAD \\
\hline Furfuryl dehydrogenase (FDH) & Furfuryl alcohol $\leftrightarrow$ furfural & NAD \\
\hline $\begin{array}{l}\text { Glucose-6-phosphate dehydrogenase } \\
\text { (G-6-PDH) }\end{array}$ & $\begin{array}{l}\text { Glucose-6-phosphate } \rightarrow \\
\text { 6-phosphogluconate }\end{array}$ & NADP \\
\hline $\begin{array}{l}\text { 6-Phosphogluconic dehydrogenase } \\
\text { (6-PGDH) }\end{array}$ & $\begin{array}{l}\text { 6-Phosphogluconate } \rightarrow \\
\text { ribulose-5-phosphate }\end{array}$ & NADP \\
\hline NAD diaphorase & $\mathrm{NADH} \leftrightarrow \mathrm{NAD}^{++}+\mathrm{H}^{+}$ & NAD \\
\hline NADP diaphorase & $\mathrm{NADPH} \leftrightarrow \mathrm{NADP}^{+}+\mathrm{H}^{+}$ & NADP \\
\hline
\end{tabular}

(4) GDH-concerned with breakdown of protein and its entry into the citric acid cycle, or with divergence of $\alpha$-ketoglutarate from the cycle into protein synthesis.

ADH-concerned with alcohol degradation.

FDH-which may be concerned with RNA degradation.

The distribution of these enzymes did not correspond with any of the major metabolites examined.

\section{Group 1}

At implantation lipid is found mainly in the epithelium lining the uterine cavity where it persists unchanged until the epithelium degenerates-which occurs at 7 days antimesometrial to the embryo, 8 days mesometrial to the 
embryo, and $8 \frac{1}{2}$ days mesometrial to that. Traces of lipid are found in the secondary decidua from $6 \frac{1}{2}$ days onwards.

Immediately before degeneration $\alpha \mathrm{GPDH}$ and $\beta \mathrm{OHDH}$ activities are observed in the epithelium (Pl. 1, Fig. 1), appearing fairly intensely at the mesometrial end of the lumen (less so antimesometrial to that) and then gradually disappearing as the epithelium degenerates.

Trace activity is observed with both enzymes in the secondary decidua from $7 \frac{1}{2}(\beta \mathrm{OHDH})$ or $9 \frac{1}{2}(\alpha \mathrm{GPDH})$ days onwards.

\section{Group 2}

The appearance of the primary decidua during implantation is accompanied by RNA accumulation in its cells. By $6 \frac{1}{2}$ days the conversion of primary to secondary decidua has occurred, and the latter contains RNA (although in lesser amount) whose concentration remains reasonably constant until the end of the period examined, when it tends to fall off to a certain extent.

Lateral to the secondary decidua, and antimesometrially, the stroma cells contain more RNA than those in the decidua. Antimesometrially, as the stroma becomes compressed laterally, the concentration falls off, particularly from 8 days onwards; mesometrially, however, the concentration initially increases both in the region destined to form the decidua basalis and the glycogen wings, although in the latter fall off in staining intensity from 8 days again occurs.

G-6-PDH and 6-PGDH are enzymes of the pentose shunt pathway, which may be linked to RNA production. The former, but not the latter, is markedly present in the primary decidua at $5 \frac{1}{2}$ days, and both enzymes appear at $6 \frac{1}{2}$ days in the secondary decidua where they persist in trace concentrations until 8 days (6-PGDH) or the end of the period examined (G-6-PDH). No activity is observed in the antimesometrial stroma; however, the mesometrial stroma, excluding the glycogen wings, shows quite intense activity (particularly centrally) from $6 \frac{1}{2}$ days (Pl. 1, Fig. 2) till the end of the period examined. Here again, the activity is greater with G-6-PDH than 6-PGDH and falls off in intensity from 8 days onwards. No activity is observed in the glycogen wings with either enzyme, and the luminal epithelium shows trace activity with G-6-PDH at the mesometrial end until epithelial degeneration occurs.

\section{Group 3}

The enzymes of this group are localized heavily in the uterine epithelium, in which they reach maximal intensity of staining shortly before degeneration when they rapidly decrease in amount. A zone of intense staining is also observed in the secondary decidua (Pl. 1, Figs. 3 and 4) in which the enzymes reach their maxima over the period 7 to $8 \frac{1}{2}$ days, and then decline in activity. Lateral to the decidua, the stroma shows intense coloration which decreases as it is traced further laterally, and here again some falling off in intensity is observed towards $10 \frac{1}{2}$ days, more particularly antimesometrially than mesometrially in the future decidua basalis.

The period of decreasing activity described above is accompanied by an accumulation of enzyme activity in the glycogen wing region which is seen as persistence of staining there, whilst that in the stroma, from which it is differen- 
tiating, tails off. As in the secondary decidua, LDH (Pl. 2, Fig. 5) and SDH staining is more intense than IDH and $\mathrm{MDH}$ : however, a reversal of that situation is seen in the primary decidua, in which the maximal staining $(++)$ observed with this group of enzymes is found with IDH (Pl. 2, Fig. 6) while LDH, SDH and MDH only reach + intensity.

$\mathrm{ME}$ is found only in the secondary decidua where it reaches + activity at $7 \frac{1}{2}$ to 8 days and then tails off.

\section{Group 4}

GDH activity is observed only occasionally and, in the tissues excluding the embryo, reaches trace levels first in the uterine epithelium at the mesometrial end just before degeneration and then in the secondary decidua towards $10 \frac{1}{2}$ days.

ADH activity ( $\mathrm{Tr}$ ) is observed in all areas of the uterine epithelium, but particularly mesometrially, for $24 \mathrm{hr}$ preceding degeneration. In the secondary decidua it reaches trace levels of activity briefly at $7 \frac{1}{2}$ days.

FDH is distributed similarly to ADH but persists in trace amounts from the beginning of the period examined to the time of degeneration (epithelium) or to the end of the period (secondary decidua). In the glycogen wings it appears from $8 \frac{1}{2}$ to $10 \frac{1}{2}$ days in increasing intensity. Its distribution in the stroma, however, differs from that of the other enzymes examined. It is present in trace amounts throughout the period examined, but from $8 \frac{1}{2}$ days on, is found only antimesometrially, the mesometrial region (except the glycogen wings) being negative. Trace activity is also observed with this enzyme in the primary decidua.

Throughout the period examined, the maternal blood vessels show ++ activity with LDH and NADH, + activity with $\mathrm{MDH}$ and NADPH, trace activity with ME, G-6-PDH, 6-PGDH, $\alpha$ GPDH, SDH, IDH and FDH, and negative with ADH, GDH and BOHDH. Both muscle layers are + active with LDH, NADH and MDH, trace active with NADPH, FDH and SDH, and negative with the remaining enzymes examined.

\section{Group 1}

EMBRYONIC TISSUES

Lipid occurs in the implanting rat embryo initially in the trophoblast and inner cell mass, and later in their derivatives - the ectoplacental cone, maximal at 8 to $8 \frac{1}{2}$ days, when the latter is exposed to the degenerating uterine lumen, and then decreasing; the giant cells, where it remains static at + to ++ positive; the visceral endoderm reaching ++ positive by $9 \frac{1}{2}$ days in the yolk sac endoderm, although embryonic endoderm and parietal endoderm remain negative; and the ectoderm and mesoderm trace amounts. Enzymatically $\beta$ OHDH (but not $\alpha \mathrm{GPDH}$ ) is found in the trophoblast, and both enzymes accumulate in the ectoplacental cone and giant cells at $9 \frac{1}{2}$ to $10 \frac{1}{2}$ days, particularly in the central part of the cone. The yolk sac endoderm shows only $\beta$ OHDH at $9 \frac{1}{2}$ to $10 \frac{1}{2}$ days, but traces of both enzymes are seen in the embryonic endoderm (Pl. 2, Fig. 7). 


\section{Group 2}

RNA is present in the trophoblast from $5 \frac{1}{2}$ days, reaching a maximum $(++)$ at $6 \frac{1}{2}$ to 7 days, and thereafter decreasing in concentration, except in the abembryonic giant cells in which the higher level is maintained, as it is in the lateral giant cells when they differentiate. Initially the ectoplacental cone shows higher concentration of RNA than that present in the trophoblast $(+++)$, but quickly reverts to the level of the giant cells, and remains so thereafter.

The inner cell mass also shows +++ and this concentration is maintained until it differentiates into the primary germ layers wherein the ectodermal concentration remains high but less staining is shown by the mesoderm $(++)$, and least by the parietal endoderm $(+)$. Initially the visceral endoderm shows ++ to +++ staining which is maintained in the brush border when it differentiates at 8 days although cytoplasmic staining becomes considerably less $(+)$. On further differentiation into yolk-sac and embryonic endoderm, the cytoplasmic staining remains at the + level.

G-6-PDH activity appears in the trophoblast and abembryonic giant cells at 7 days and accumulates in the latter to +++ activity, but decreases in the trophoblast as it disappears. When the lateral giant cells appear at $9 \frac{1}{2}$ days, however, they quickly accumulate large quantities of the enzyme and exhibit a similar staining reaction to the abembryonic group. Slight activity is seen in the ectoplacental cone at 7 days and increases rapidly, particularly centrally. Both layers of endoderm show + activity from 7 (visceral) or $9 \frac{1}{2}$ (parietal) days onwards (Pl. 2, Fig. 8) and when the visceral layer differentiates into yolk-sac and embryonic endoderm, the latter accumulates further activity. Ectoderm, mesoderm and amnion all show + activity as did the inner cell mass from which they are derived.

Similar, but less intense, staining is found with 6-PGDH.

\section{Group 3}

The results observed in embryonic tissues with these enzymes are summarized in Table 2.

All except ME are found in the trophoblast (Pl. 2, Fig. 6) where they gradually decrease in intensity as it thins out and disappears. In the tissues to which it gives rise, however--the abembryonic (Pl. 3, Fig. 9) and lateral giant cells, and the ectoplacental cone-activity increases further (to maximal or near-maximal levels) and, towards $10 \frac{1}{2}$ days, ME activity also appears. In the ectoplacental cone at $9 \frac{1}{2}$ and $10 \frac{1}{2}$ days, the enzyme activity is greater centrally than peripherally (PI. 3, Fig. 10).

The inner cell mass initially shows similar but lesser enzyme activities than the trophoblast. Thereafter $\mathrm{LDH}$ and IDH decrease, although SDH and MDH increase to their maxima at 7 days, after which SDH maintains that level while MDH falls off in activity. When the visceral and parietal layers of endoderm differentiate the enzymes appear in them also, their levels remaining static (visceral layer) or accumulating slowly (parietal layer +; Pl. 3, Fig. 9). Interesting changes are observed when the visceral layer differentiates into yolk-sac and embryonic endoderm. All enzyme activities decrease in the embryonic region (Pl. 3, Fig. 9) and two (LDH, SDH) in the yolk-sac region also. In the 
TABle 2

\begin{tabular}{|c|c|c|c|c|c|c|c|c|c|}
\hline & \multicolumn{9}{|c|}{ Days } \\
\hline & $5 \frac{1}{2}$ & $6 \frac{1}{2}$ & 7 & $7 \frac{1}{2}$ & 8 & $8 \frac{1}{2}$ & $9 \frac{1}{2}$ & $10 \frac{1}{2}$ & \\
\hline $\begin{array}{l}\text { Trophoblast } \\
\text { LDH } \\
\text { IDH } \\
\text { SDH } \\
\text { MDH } \\
\text { ME }\end{array}$ & $\begin{array}{c}+++ \\
+ \\
+ \\
++\end{array}$ & $\begin{array}{l}++ \\
+ \\
++ \\
++\end{array}$ & $\begin{array}{l}++ \\
\text { Tr } \\
++ \\
++ \\
-\end{array}$ & $\begin{array}{l}+ \\
\mathbf{T r} \\
\mathbf{T r} \\
+ \\
-\end{array}$ & & & & & \\
\hline $\begin{array}{l}\text { Ectoplacental } \\
\text { cone } \\
\text { LDH } \\
\text { IDH } \\
\text { SDH } \\
\text { MDH } \\
\text { ME }\end{array}$ & & $\begin{array}{l}++ \\
++ \\
+\end{array}$ & $\begin{array}{l}++ \\
+ \\
++ \\
+\end{array}$ & $\begin{array}{c}++ \\
+\overline{+} \\
++ \\
+\end{array}$ & $\begin{array}{c}++ \\
++ \\
++ \\
++\end{array}$ & $\begin{array}{c}++ \\
++ \\
+++ \\
++ \\
+\mathbf{T r}\end{array}$ & $\begin{array}{r}+\mathbf{L}+++\mathbf{C} \\
+\mathbf{L}++\mathbf{C} \\
++\mathbf{L}++\mathbf{C} \\
+\mathbf{L}+++\mathbf{C} \\
\mathbf{T r L}++\mathbf{C}\end{array}$ & $\begin{array}{r}+\mathbf{L}+++\mathbf{C} \\
+\mathbf{L}++\mathbf{C} \\
++\mathbf{L}++\mathbf{C} \\
+\mathbf{L}+++\mathbf{C} \\
\mathbf{T r} \mathbf{L}++\mathbf{C}\end{array}$ & \\
\hline $\begin{array}{l}\text { Giant cells } \\
\text { (abembryonic) } \\
\text { LDH } \\
\text { IDH } \\
\text { SDH } \\
\text { MDH } \\
\text { ME } \\
\end{array}$ & & & $\begin{array}{c} \pm \\
\pm+ \\
++ \\
+\end{array}$ & $\begin{array}{c}++ \\
\text { Tr } \\
+++ \\
+ \\
+\end{array}$ & $\begin{array}{c}++ \\
+T^{+} \\
++ \\
+\end{array}$ & $\begin{array}{c}++ \\
\mathbf{T r} \\
++ \\
+\end{array}$ & $\begin{array}{c}++++ \\
++ \\
+++ \\
++ \\
++\end{array}$ & $\begin{array}{c}+++ \\
++++ \\
+++ \\
++++ \\
+++\end{array}$ & \\
\hline $\begin{array}{l}\text { Giant cells } \\
\text { (lateral) } \\
\text { LDH } \\
\text { IDH } \\
\text { SDH } \\
\text { MDH } \\
\text { ME } \\
\end{array}$ & & & & & & & $\begin{array}{c}++t \\
+++ \\
+++ \\
+++ \\
+\end{array}$ & $\begin{array}{c}++t \\
++ \\
+++ \\
+++ \\
++\end{array}$ & \\
\hline $\begin{array}{l}\text { Inner cell } \\
\text { mass } \\
\text { IDH } \\
\text { IDH } \\
\text { SDH } \\
\text { MDH } \\
\text { ME }\end{array}$ & $\begin{array}{l}++ \\
+ \\
+ \\
+ \\
+\end{array}$ & $\begin{array}{l}+ \\
+ \\
+ \\
+\end{array}$ & $\begin{array}{c}+ \\
\mathbf{T r} \\
+++ \\
++ \\
+\end{array}$ & $\begin{array}{c}+ \\
+ \\
+ \\
+\end{array}$ & $\underset{+\frac{t}{+}}{+}$ & & & & \\
\hline 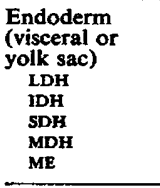 & & & $\begin{array}{l}++ \\
++ \\
++ \\
+\end{array}$ & $\begin{array}{c}++ \\
+ \\
++ \\
++ \\
-\end{array}$ & $\begin{array}{c}++ \\
+ \\
++ \\
+ \\
+\end{array}$ & $\begin{array}{c}++ \\
+ \\
++ \\
++ \\
+\end{array}$ & $\begin{array}{c}+ \\
+ \\
++ \\
+ \\
+\end{array}$ & $\begin{array}{c}+ \\
+ \\
++ \\
+ \\
+\end{array}$ & \\
\hline $\begin{array}{l}\text { Endoderm } \\
\text { (embryonic) } \\
\text { LDH } \\
\text { IDH } \\
\text { SDH } \\
\text { MDH } \\
\text { ME }\end{array}$ & & & & & & & $\begin{array}{l}\mathbf{T r} \\
\mathbf{T r} \\
+ \\
\mathbf{T r} \\
+\end{array}$ & $\begin{array}{l}+ \\
\mathbf{T r} \\
+ \\
+ \\
\mathbf{T r}\end{array}$ & $\begin{array}{c}(3+\quad A \text { and } P) \\
(2+3+) \\
(1+2+\cdots\end{array}$ \\
\hline $\begin{array}{l}\text { Endoderm } \\
\text { (parietal) } \\
\text { LDH } \\
\text { IDH } \\
\text { SDH } \\
\text { MDH } \\
\text { ME }\end{array}$ & & & & $\begin{array}{l}+ \\
\mathbf{T r} \\
++ \\
+ \\
+\end{array}$ & $\begin{array}{l}++ \\
+ \\
++ \\
+\end{array}$ & $\begin{array}{l}++ \\
+ \\
++ \\
+\end{array}$ & $\begin{array}{l}++ \\
+ \\
++ \\
+ \\
+\end{array}$ & $\begin{array}{l}++ \\
++ \\
++ \\
+ \\
+\end{array}$ & \\
\hline $\begin{array}{l}\text { Ectoderm } \\
\text { LDH } \\
\text { IDH } \\
\text { SDH } \\
\text { MDH } \\
\text { ME }\end{array}$ & & & & & $\begin{array}{l}++ \\
\text { Tr } \\
++ \\
+ \\
+\end{array}$ & $\begin{array}{c}+\underset{T r}{+} \\
+++ \\
++\end{array}$ & $\begin{array}{l}\mathbf{T r} \\
\mathbf{T r} \\
+ \\
\mathbf{T r} \\
\mathbf{T r}\end{array}$ & $\begin{array}{l}\mathbf{T r} \\
\mathbf{T r} \\
\mathbf{T r} \\
\mathbf{T r} \\
\mathbf{T r}\end{array}$ & \\
\hline $\begin{array}{l}\text { Mesoderm } \\
\text { LDH } \\
\text { IDH } \\
\text { SDH } \\
\text { MDH } \\
\text { ME } \\
\end{array}$ & & & & & $\begin{array}{c}\overline{\mathbf{T r}} \\
++ \\
\pm \\
+\end{array}$ & $\begin{array}{c}++ \\
+ \\
++ \\
++\end{array}$ & $\begin{array}{l}+ \\
+ \\
+ \\
+ \\
+\end{array}$ & $\begin{array}{r}+ \\
+ \\
+ \\
++ \\
\mathbf{T r}\end{array}$ & 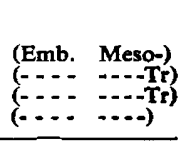 \\
\hline $\begin{array}{l}\text { Amnion } \\
\text { LDH } \\
\text { IDH } \\
\text { SDH } \\
\text { MDH } \\
\text { ME }\end{array}$ & & & & & & & $\begin{array}{l}+ \\
\text { Tr } \\
+ \\
+ \\
+\end{array}$ & $\begin{array}{l}+ \\
\operatorname{Tr} \\
+ \\
+ \\
-\end{array}$ & \\
\hline
\end{tabular}

A-anterior intestinal portal; $\mathrm{P}$ - posterior intestinal portal; $\mathbf{L}-$ Lateral part of ectoplacental cone; $\mathbf{C}-$ Central part of ectoplacental cone. 
anterior and posterior intestinal portals of the embryo, however, marked concentrations of $\mathrm{LDH}, \mathrm{MDH}, \mathrm{IDH}$ and SDH appear (Pl. 3, Fig. 11) unlike the remaining embryonic endoderm ( + or $\mathrm{Tr}$ activity). In both sites ME appears.

In the remaining tissues derived from the inner cell mass-ectoderm and mesoderm-LDH, IDH, SDH and MDH activities increase to their maxima at about $8 \frac{1}{2}$ days (Pl. 3, Fig. 12). Thereafter their activity falls off and ME appears. At $10 \frac{1}{2}$ days the embryonic mesoderm shows less activity than the extra-embryonic mesoderm with all enzymes.

The amnion shows $\operatorname{Tr}$ to + staining with all enzymes of this group except ME.

\section{Group 4}

$G D H$. This enzyme only appears at $10 \frac{1}{2}$ days in $\operatorname{Tr}$ amounts in the parietal endoderm and ectoderm and + amounts in the mesoderm, abembryonic and lateral giant cells, and centre of the ectoplacental cone.

$A D H$. At $9 \frac{1}{2}$ days this enzyme is found in trace amounts in both yolk-sac and parietal endoderm (but not embryonic endoderm), in the ectoderm and mesoderm, and in the giant cells. More activity $(+)$ occurs in the centre of the ectoplacental cone. Activity in the ectoderm, mesoderm and giant cells increases to + at $10 \frac{1}{2}$ days, accompanied by appearance of the enzyme in the embryonic endoderm also, but the yolk sac and parietal endoderm reaction does not alter.

$F D H$. This enzyme is absent from the trophoblast, but is seen in its derivatives at $9 \frac{1}{2}$ to $10 \frac{1}{2}$ days where it accumulates to ++ levels (centre of ectoplacental cone only). Initially the inner cell mass is negative, but some activity accumulates (again to ++ levels) in the yolk-sac, and parietal and embryonic endoderm over the same period (Pl. 3, Fig. 13). Ectoderm and mesoderm show + activity at $10 \frac{1}{2}$ days.

\section{DIAPHORASES}

With the exception of the implantation zone over $7 \frac{1}{2}$ to $8 \frac{1}{2}$ days, and the most lateral part of the stroma, in both cases with NADPH, no tissue was found in this study which did not contain sufficient quantities of NAD or NADP diaphorase to give a coloration with Nitro-BT.

However, the glycogen wings, in the latter part of the period examined, showed less activity for NADP diaphorase than might have been expected in this relatively active area.

\section{DISCUSSION}

No previous histochemical analysis of the carbohydrate, lipid and RNA metabolic pathways of the tissues surrounding and including the implanting rat embryo has been made. Previous related studies have been concerned purely with the distribution of glycogen (Krehbiel, 1937; Bridgman, 1948; Christie, 1966) or lipid (Krehbiel, 1937; Bridgman, 1948; Alden, 1948) or RNA (Krehbiel, 1937), or have been concerned with later stages (Wislocki, Deane \& Dempsey, 1946; Padykula, 1958; Padykula \& Richardson, 1963).

The distributions of lipid and RNA described above substantially agree with 
the above authors, a more exact interpretation of the RNA distribution having been facilitated by the method localizing only DNA and RNA at $\mathrm{pH} 1.64$ (see Pearse, 1960), ribonuclease controls showing only nuclear staining, with vacuolated nucleoli.

The specificity of the dehydrogenase techniques has also to be considered. Recently Kalina, Gahan \& Jones (1965) suggested that all histochemically demonstrated dehydrogenase reactions merely show the localization of one or other pyridine nucleotide diaphorase. Were this the case, one would expect results demonstrating identical localizations of activity with all substrates, differing only in overall intensity depending on the degree to which the substrate used was dehydrogenated. However, this study shows totally different pictures with different groups of enzymes. Also, considerable quantities of poly-vinyl-pyrrolidone were added to the incubation media to minimise diffusion of enzyme, a precaution which was not taken by Kalina, Gahan \& Jones in their work.

The risk of enzyme diffusion applies particularly to the lactic dehydrogenase system, where the enzyme is mucopolysaccharide in nature, and therefore more prone to diffusion into the medium, or into areas of tissue section which should give a negative reaction. Suggestions that the observed reaction is specific are found in Table 2 where negatively reacting tissue (e.g. the mesoderm at 8 days) lies adjacent to a positive area; also in the lack of discoloration of the incubation medium (due to diffusion of enzyme into it) for several hours after the sections had been removed from it, whereas the omission of PVP produced discoloration even before the sections themselves had stained.

As the above observations suggest enzymic specificity it is of interest to examine the observed pathways of metabolism of carbohydrate, lipid and RNA in relation to the implanting rat embryo; to speculate upon the sources of histiotrophic nutrition of the embryo, and the part played therein by the decidua and glycogen wings.

\section{Group 1}

The appearance of $\alpha \mathrm{GPDH}$ and $\beta \mathrm{OHDH}$ in the uterine epithelium before degeneration corresponds to the lipid content. It immediately succeeds maximal staining intensity in this site for non-specific esterase (Christie, unpublished observations), which enzyme may be concerned with lipid breakdown to $\alpha$-glycero-phosphate and fatty acids, for further metabolism by $\alpha$ GPDH or $\beta$ OHDH respectively (Text-fig. 1). The abrupt disappearance of these enzymes from the epithelium just before degeneration presumably expresses metabolic cell death before histologic degeneration.

In the decidua and embryonic tissues, both enzymes correspond to the distribution of lipid and may be concerned with its breakdown. Two areas are of particular interest. First is the yolk-sac endoderm in which lipid accumulates from $8 \frac{1}{2}$ days onwards and, although traces of $\beta$ OHDH are seen, no $\alpha \mathrm{GPDH}$ is found. This may be an expression of the storage, rather than the breakdown of the lipid. The second is the embryonic endoderm where both enzymes, but not lipid, appear. It may be that they are here concerned with absorption of lipid from the yolk-sac fluid, although this has not as yet been shown to be present. 


\section{Group 2}

Excluding the embryo, four areas show correlation between G-6-PDH and 6-PGDH, and RNA distribution: the primary decidua, the secondary decidua, the glycogen wings, and the mesometrial stroma.

In the primary decidua simultaneous accumulation of RNA and G-6-PDH occurs (although not 6-PGDH) and their appearance there together would suggest that ribose for RNA production in this site can arise via the pentose shunt (Text-fig. 1). The absence of 6-PGDH from this site remains inexplicable.

The RNA increase is of particular interest, as primary decidua development corresponds temporally with the oestrogen 'surge' (Mayer, 1963) and oestrogen injection increases RNA synthesis in the uterus of immature rats (Gorski \& Nelson, 1965). This finding further confirms and supplements the previous suggestion (Christie, 1966) that the oestrogen surge may primarily increase the levels of ATPase activity in the uterus, RNA synthesis being known to decrease uterine ATP levels under oestrogen stimulation (Aaronson, Natori \& Tarver, 1965).

An association between the pentose shunt and RNA production is again suggested by the decrease in RNA concentration with conversion of primary to secondary decidua, and the concomitant marked decrease in G-6-PDH and 6-PGDH activities and, contrastingly, in the associated increase in RNA and enzyme activity in the mesometrial stroma.

The low RNA, G-6-PDH, and 6-PGDH concentrations in the glycogen wings, must be interpreted with caution, as the enzymes depend for their demonstration on NADP diaphorase activity whose low levels of activity have been described, and will be discussed below.

In the embryo the correlation between RNA content and G-6-PDH and 6-PGDH activities continues, for example, in the trophoblast and its giant cells. However, in the ectoplacental cone considerable quantities of G-6-PDH and 6-PGDH activities accumulate (particularly centrally) towards $10 \frac{1}{2}$ days without a corresponding increase in RNA and with a rapid accumulation of glycogen. The explanation of these observations may perhaps be found in the rapid enlargement of the ectoplacental cone which is taking place; this presumably requires increased protein synthesis and therefore increased RNA (messenger RNA) turnover. In this respect the concomitant increase in FDH in this site is of interest (see below).

\section{Group 3}

The metabolic pathways relevant to carbohydrate, lipid and RNA, and the points of action of the enzymes studied are indicated in Text-fig. 1.

The breakdown of glycogen either via the pentose shunt or alternatively to pyruvate is shown. From pyruvate it follows one of two courses, depending on the state of oxygenation in the cell. Anaerobically it is converted into lactate by $\mathrm{LDH}$, but aerobically it passes through the Krebs' cycle via IDH, SDH and MDH. Further interconversions (not shown) are possible, one of interest in this study being the NADP-linked conversion of malate to pyruvate which may be the $\mathrm{ME}$ demonstrated here, and is involved in the reversal of glycolysis. Certainly the distribution of $\mathrm{ME}$ differed totally from $\mathrm{MDH}$, and it accumulated in sites, 
e.g. the visceral endoderm, commencing to accumulate glycogen (Bridgman, 1948).

Relevant to this group of enzymes, the areas of non-embryonic tissues of particular interest are (1) the antimesometrial decidua and stroma in which glycogen accumulates up to $7 \frac{1}{2}$ days, the accumulation proceeding from the

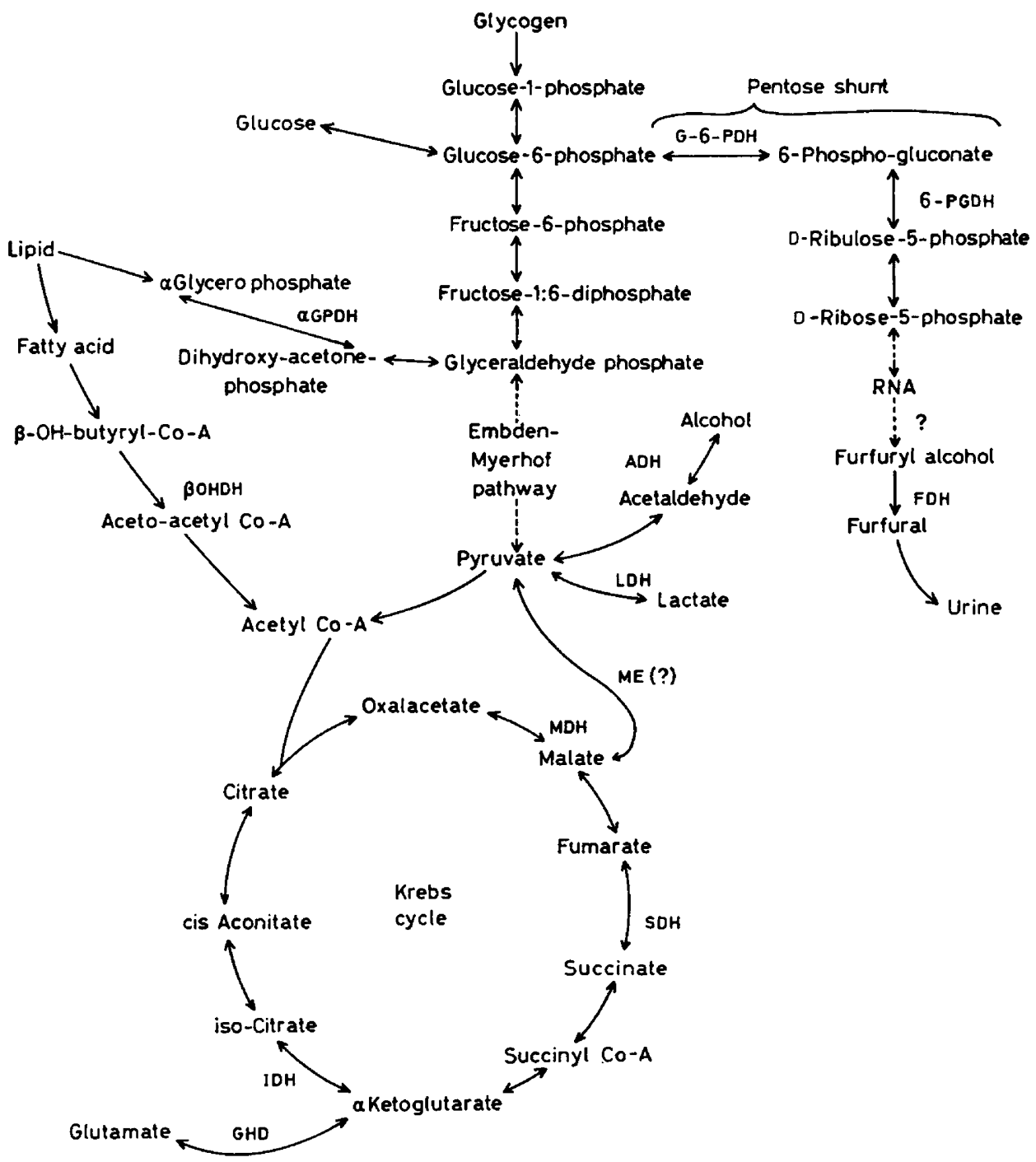

TeXT-FIG. 1. Main carbohydrate, lipid and RNA metabolic pathways, showing the enzymes examined in this study.

centre outwards, and being followed from $6 \frac{1}{2}$ to $9 \frac{1}{2}$ days by a similarly proceeding disappearance; and (2) the mesometrial stroma and glycogen wings in which gradual accumulation from 7 days onwards occurs.

In the first of these areas, $\mathrm{LDH}, \mathrm{SDH}, \mathrm{MDH}$ and ME show (from $6 \frac{1}{2}$ to $8 \frac{1}{2}$ days) intense staining decreasing laterally. At $8 \frac{1}{2}$ days the activity begins to decrease. 
Thus the enzyme is distributed in the area of glycogen breakdown and, when all glycogen has been metabolized, the enzyme activity tails off. The intense glycolytic activity in this site, with much less activity of G-6-PDH and 6-PGDH, suggests glycogen breakdown via the Embden-Myerhof pathway, rather than via the pentose shunt. Beyond pyruvate marked activity of both anaerobic (LDH) and aerobic (MDH, SDH) pathways is here demonstrated, but it seems unlikely that cells will metabolize simultaneously aerobically and anaerobically. Evidence favouring the LDH pathway in this actively proliferating tissue is given by Dickson (1966), who has shown that cancer cells tend to metabolize anaerobically; in the observations of Villee \& Hagerman (1953), Gordon \& Villee (1955) and Villee (1962) who have shown that decreasing oestrogen concentration, which occurs in the maternal blood supplying these cells, is accompanied by less complete oxidation of glucose; and in the effect noted by Bever (1959) who, working on the uterus of ovariectomized rats, showed that progesterone increase (present in pregnant rats) is accompanied by increasing LDH activity. That the cells are gaining some of their energy requirements from aerobic metabolism, however, is suggested by the intense sDH activity, and slightly less MDH. In any event, whatever the route, considerable energy production is obviously proceeding in these cells, and the breakdown of glycogen may be not only to glucose-6-phosphate and thence to glucose as suggested previously (Christie, 1966), but also to more complete oxidation. The quantities of RNA present in the decidua suggest that the energy produced may be used for protein synthesis.

In the glycogen wings glycogen accumulation is not accompanied by any alteration in these enzyme activities, and the only change suggestive of decreased oxidation of glucose is a fall-off of SDH concentration at $10 \frac{1}{2}$ days. It can only be assumed either that decrease in glucose oxidation for glycogen synthesis in this site is too gradual to be detected histochemically, or that the glucose for glycogen synthesis is coming directly from the maternal blood stream.

In the embryo, glycogen is seen in wave-like cycles of deposition and loss. One extends from the commencement of the period examined to $9 \frac{1}{2}$ days in the trophoblast and certain structures derived therefrom-abembryonic and lateral giant cells, although not the ectoplacental cone where central accumulation occurs. A second extends from 6 to $9 \frac{1}{2}$ days in the inner cell mass, parietal endoderm and visceral, later to become yolk-sac, endoderm. A third from $7 \frac{1}{2}$ to $9 \frac{1}{2}$ days in the ectoderm, mesoderm, embryonic endoderm and amnion.

This third group of enzymes shows in embryonic structures, as might be expected, decreasing staining with lessening importance of the trophoblast and inner cell mass. However, the tissues derived from these two structures diverge markedly in staining pattern. Enzyme activity accumulates in the ectoplacental cone and giant cells, while a wave-like increase and decrease occurs in the ectoderm, mesoderm and endoderm (except the parietal layer). The ectoplacental cone, giant cells and parietal endoderm are much concerned with transport of substances from the decidua and maternal blood circulating around the chorionic vesicle into the yolk-sac cavity for embryonic nutrition. As the embryo enlarges, so the importance of such transport increases, certainly to the development of the chorio-allantoic placenta, which occurs later than the end 
of this study. Thus, increased staining in these sites with increasing embryonic size may be associated with increased transport, the energy for which presumably comes largely from glycolysis. In the ectoderm, mesoderm and endoderm, on the other hand, the main energy requirements at this stage are for mitosis, the energy source for which, at least in developing epithelia (Bullough, 1952; Sorokin, Padykula \& Herman, 1959), is known to be glycogen. Thus, in this study, the peak of the wave of enzyme activity in each of these tissues follows 12 to $24 \mathrm{hr}$ after the decrease in glycogen concentration, suggesting that glycogen is metabolized in this site via glycolysis for energy production for mitosis, enzyme activity falling off, when the glycogen has been expended, to 'resting' levels. The fall-off of enzyme activity in the yolk-sac endoderm is rather surprising. This tissue is probably concerned with the absorption of at least non-diffusible substances from the yolk-sac cavity, presumably for breakdown and transport to the embryo for its nutrition; it would, therefore, seem likely that, as in the giant cells and parietal endoderm, increasing activity with increasing embryonic size would occur. Two possible explanations of this observation are:

(1) The level of enzyme activity reached at $9 \frac{1}{2}$ to $10 \frac{1}{2}$ days is adequate for energy requirements, and the previous higher level is an expression of excessive glycogen breakdown, associated with morphogenesis.

(2) The yolk-sac endoderm absorbs non-diffusible substances from the yolksac cavity, metabolizes them to simpler substances, and then secretes them back out into the cavity, whence they gain direct access to the embryo for absorption. By this route the metabolites would not be required to be transported through the basement membrane of the yolk-sac endoderm and presumably less energy expenditure would be required.

Slight evidence in favour of the second suggestion above is seen in the observations previously reported (Christie, 1966) of a lack of adenosinetriphosphatase (concerned with transport across cell membranes) in the bases of the yolk-sac endoderm, and of the presence in the Golgi zone of the endoderm of considerable quantitites of thiamine pyrophosphatase (found in the Golgi membranes and presumably associated therewith in the process of secretion). The marked increase in enzyme (LDH, MDH, IDH and SDH) activity in anterior and posterior intestinal portals, while possibly related simply to morphogenesis, may also be an indication of increased absorption by the embryonic endoderm.

\section{Group 4}

The function of only GDH in this group is definitely known. It is concerned with protein breakdown and introduction into the Krebs' cycle, or in the reverse direction, with the diversion of $\alpha$-ketoglutaric acid into amino-acid and protein synthesis. Thus the appearance of the enzyme in the ectoplacental cone, mesoderm and giant cells-all sites of cellular proliferation and therefore protein synthesis - may be an expression of such processes there; its presence in the yolk-sac endoderm correlates with its function in breaking down substances for embryonic nutrition.

Association between FDH and decreasing RNA concentration has been noted previously. Ribose, from RNA, is degraded at least in chemical reactions to 
furfural, which could be produced from furfuryl alcohol by FDH, and which is secreted in the urine. In this study increasing FDH concentration occurs either with decreasing RNA concentration (e.g. secondary decidua) or where rapid RNA turnover, due to active protein synthesis may be taking place (e.g. the ectoplacental cone, giant cells, ectoderm, mesoderm or glycogen wings). Therefore this enzyme may have some place in the degradation of RNA at least in these sites. That the staining of this enzyme was not due to non-specific alcohol dehydrogenase is shown by the observed differences in localization from ADH.

\section{Diaphorases}

The differences in localization of diaphorase activity with NADPH as opposed to NADH, affect not only the demonstration of the other dehydrogenases, but also possibly the routes of metabolism in the tissues.

The paucity of G-6-PDH and 6-PGDH staining in the glycogen wings has been discussed previously, as has the decreased activity of IDH (NADP-linked), as opposed to the other enzymes of the Krebs' cycle (all NAD-linked) in all sites examined. It is certain that the effect with respect to IDH was not due to an NAD-linked isocitric dehydrogenase, as demonstrated in human placenta by Villee \& Gordon (1955), since no staining with isocitrate as substrate was observed if NAD was substituted for NADP in the reaction mixture.

A feature common to many of the sites showing lack of NADP diaphorase was the presence of RNA, suggesting that active protein synthesis might be taking place. It is of interest, therefore, to note (Wilson \& Siperstein, 1959) that both NADH and NADPH stimulate protein synthesis, the hydrogen being passed through several transhydrogenations, and that NADPH is by far the more active of the two.

\section{Function of the decidua}

By combining the results of this and the previous paper, it is possible to speculate upon the function of the decidua, and the part played by it in embryonic nutrition. Previously it was shown that the concentration of glucose6 -phosphatase in the decidua decreased towards $9 \frac{1}{2}$ days; it was suggested that glycogen in this site was used to provide energy for mitosis, and was also broken down to glucose-6-phosphate and thence to glucose for passage, via the maternal blood stream, to the embryo for its nutrition. However, except in cases of starvation, maternal blood glucose should be adequate for supply to the embryo, and while it would seem likely that the decidua subserves the two functions detailed above, it appears that to these a third function - the synthesis of protein and its passage to the embryo - might be added, on the basis of:

(a) The energy production via observed anaerobic and aerobic glycolysis.

(b) The RNA seen in the cells.

(c) The lack of NADP diaphorase in this site, suggesting diversion of the hydrogen from simple energy production to transhydrogenation and stimulation of protein synthesis.

(d) The very heavy ATPase activity previously noted (this enzyme being known possibly to be concerned with transport across cell membranes and/or energy production). 


\section{REFERENCES}

Aaronson, S. A., Natori, Y. \& Tarver, H. (1965) Effect of oestrogen on uterine ATP levels. Proc. Soc. exp. Biol. Med. 120, 9.

ALDEN, R. H. (1948) Implantation of the rat egg. III. Origin and development of primary trophoblast giant cells. Am. 7. Anat. 82, 143.

Bever, A. T. (1959) Steroid influences on the lactic dehydrogenase, DPNH-oxidase system of the rat uterus. Ann. N.Y. Acad. Sci. 75, 472.

Bridgman, J. (1948) A morphological study of the development of the placenta of the rat. II. An histological and cytological study of the development of the chorio-allantoic placenta of the white rat. F. Morph. 83, 195.

Bullough, W. S. (1952) The energy relations of mitotic activity. Biol. Rev. 27, 133.

Christie, G. A. (1966) Implantation of the rat embryo-glycogen and alkaline phosphatases. F. Reprod. Fert. 12, 279.

Dickson, J. A. (1966) Tissue culture approach to the trearment of cancer. Brit. med. J. i, 817.

Gordon, E. E. \& ViLLEE, C. A. (1955) Spectrophotometric studies of the stimulation of human placental preparations by oestradiol. 7 . biol. Chem. 216, 215 .

Gorski, J. \& Nelson, N. J. (1965) Ribonucleic acid synthesis in the rat uterus and its early response to oestrogen. Archs Biochem. Biophys. 110, 284.

Kalina, M., Gahan, P. B. \& Jones, G. R. N. (1965) An evaluation of the histochemical demonstration of certain pyridine nucleotide-linked dehydrogenases. Nature, Lond. 207, 647.

KrEHBIEL, R. H. (1937) Cytological studies of the decidual reaction in the rat during early pregnancy and in the production of deciduomata. Physiol. Zoöl. 10, 212.

MAYER, G. (1963) Delayed nidation in rats. Delayed Implantation, pp. 213-231. Ed. A. C. Enders. University of Chicago Press.

Mossman, H. W. (1937) Comparative morphogenesis of the fetal membranes and accessory uterine structures. Contrib. Embryol. No. 158.

Padykula, H. A. (1958) A histochemical and quantitative study of the enzymes of the rat placenta. 7. Anat. 92, 118.

Padykula, H. A. \& Richardon, D. (1963) A correlated histochemical and biochemical study of glycogen storage in the rat placenta. Am. F. Anat. 122, 215.

Pearse, A. G. E. (1960) Histochemistry-theoretical and applied. Churchill, London.

Sorokin, S., Padykula, H. A. \& Herman, E. (1959) Comparative histochemical patterns in developing mammalian lungs. Devl Biol. 1, 125.

Villee, C. A. (1962) Metabolism of the placenta. Am. 7. Obstet. Gynec. 84, 1684.

VilleE, C. A. \& Gordon, E. E. (1955) Further studies on the action of oestradiol in vitro. 7. biol. Chem. 216, 203.

VilleE, C. A. \& HagermanN, D. D. (1953) Effects of oestradiol on the metabolism of human placenta in vitro. J. biol. Chem. 205, 873.

Wilson, J. D. \& Siperstein, M. D. (1959) Studies on the relationship between glucose oxidation and intermediary metabolism. III. The influence of pyridine nucleotides on protein synthesis. $\mathcal{J}$. clin. Invest. 38, 317.

Wislocki, G. B., DeANe, H. W. \& Dempsey, E. W. (1946) The histochemistry of the rodent's placenta. Am. 7. Anat. 78, 281. 


\section{EXPLANATION OF PLATES}

Throughout these plates, the mesometrial end of the section is uppermost, except in Figs. 2, 5 and 10 , which are rotated through $90^{\circ}$. All figures are of transverse sections of the uterus.

\section{Plate 1}

Frg. 1. $\alpha$ GPDH activity is confined to the epithelium of the uterine lumen, at $7 \frac{1}{2}$ days.

FIG. 2. G-6-PDH activity is more obvious at $7 \frac{1}{2}$ days in the mesometrial stroma (s) than in the antimesometrial decidua (D). The embryo (E) shows little activity.

FIG. 3. LDH activity concentrated in the decidua (D) at $8 \frac{1}{2}$ days is visible, and tails off as it is traced laterally to the stroma (s).

FIg. 4. MDH activity at $8 \frac{1}{2}$ days is intense in the decidua (D), but almost absent from the implantation zone (I.z.).

\section{Plate 2}

FIG. 5. LDH activity is present in the glycogen wings (G.w.) at $8 \frac{1}{2}$ days, although the staining is not so intense as in the antimesometrial decidua (Fig. 3). The mesometrial stroma (M.s.) is almost unreactive for this enzyme.

FIG. 6. IDH activity accumulates markedly in the primary decidua (P.D.) and epithelium (EP.) but much less in the stroma (s). Some activity is also present in the trophoblast ( $\mathrm{r}$ )$5 \frac{1}{2}$ days gestation.

Fig. 7. Вондн activity is visible in the embryonic endoderm (E.E.), parietal endoderm (P.E.) and abembryonic giant cells (G.C.) at $9 \frac{1}{2}$ days.

FIG. 8. This figure shows the distribution of G-6-PDH activity in the mesoderm (MEs), embryonic endoderm (E.E.), yolk-sac endoderm (Y.S.), parietal endoderm (P.E.) and particularly in the abembryonic giant cells (G.c.) at $10 \frac{1}{2}$ days.

\section{Plate 3}

FIG. 9. SDH activity is seen in the embryonic structures in ectoderm (ЕСT.), endoderm (E.E.) and in the parietal endoderm (P.E.) and abembryonic giant cells (G.C.). Moderate activity is also seen in the decidua ( $D$ ).

FIG. 10. LDH activity occurs moderately at $10 \frac{1}{2}$ days in the glycogen wings (G.w.) and is concentrated more in the centre of the ectoplacental cone (E.C.) than its periphery.

FIG. 11. Glycolytic enzyme activity (in this case $\mathrm{MDH}$ ) increases markedly in anterior (A.I.P.) and posterior intestinal portals at $10 \frac{1}{2}$ days and is concentrated in the buccopharyngeal membrane (в.M.). Less activity is seen in the ectoderm (ЕСT.).

FIG. 12. MDH activity reaches maximal levels at the time of embryonic ectoderm (ECT.) and endoderm (E.E.) differentiation. Decidua (D), abembryonic giant cells (G.C.) and parietal endoderm (P.E.) also show strong positivity at this stage.

FIG. 13. FDH activity is seen in the ectoderm (ECT.), mesoderm (MEs.) and endodermsembryonic (E.E.) and parietal (P.E.) just interior to Reichert's membrance (R.M.) which separates the latter from the abembryonic giant cells (G.G.) and less positive decidua (D). $10 \frac{1}{2}$ days gestation. 
PLATE 1
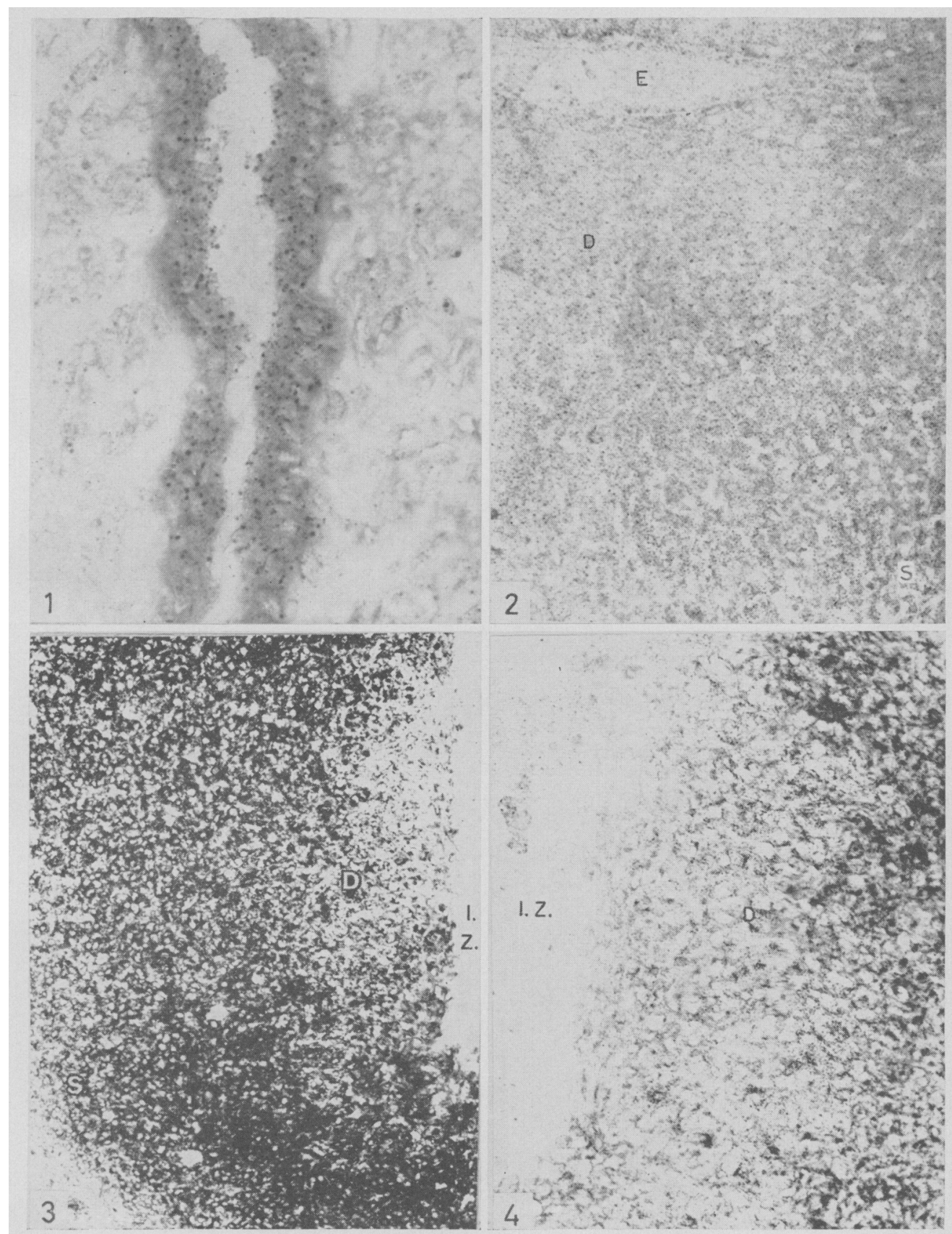
PLATE 2

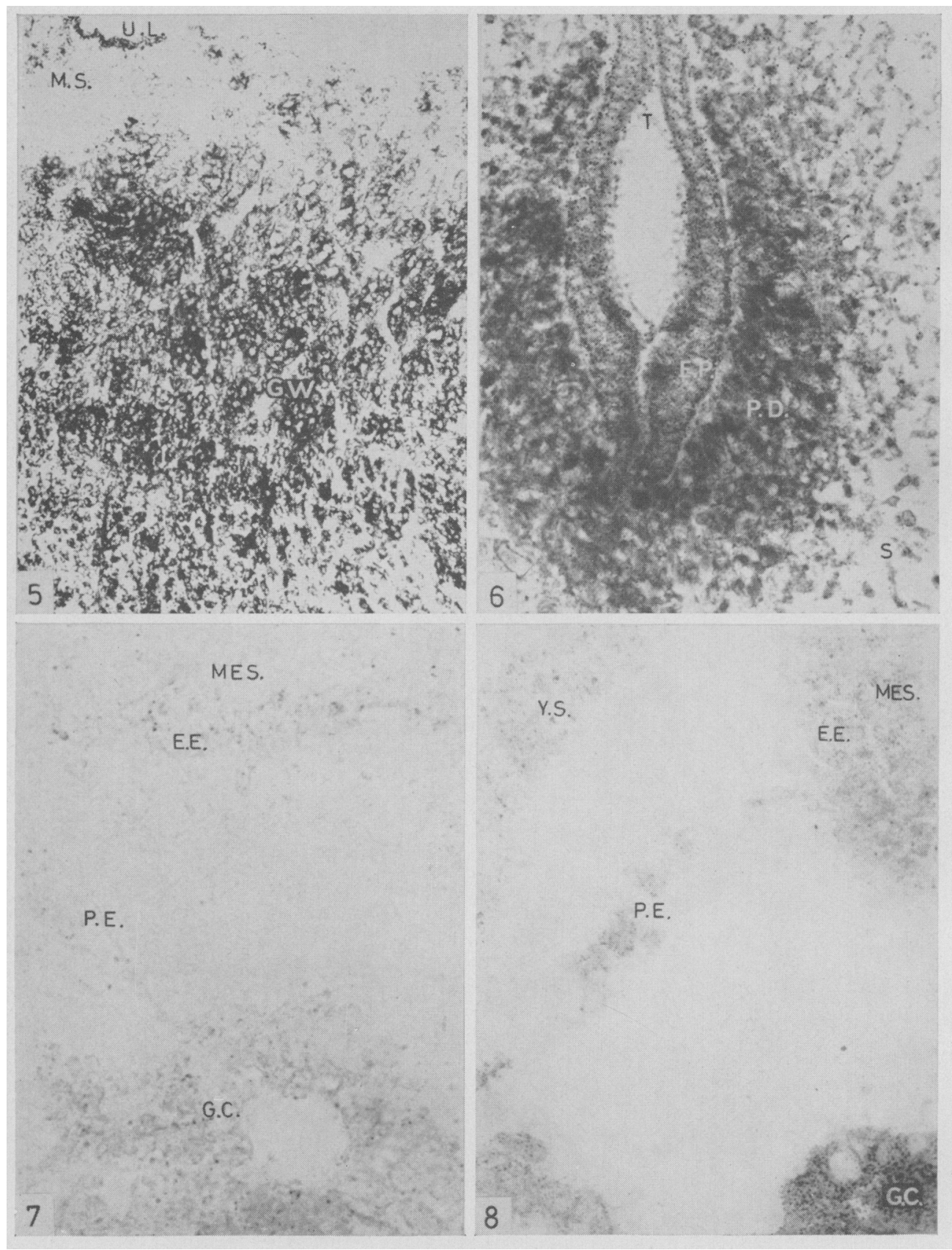


PLATE 3

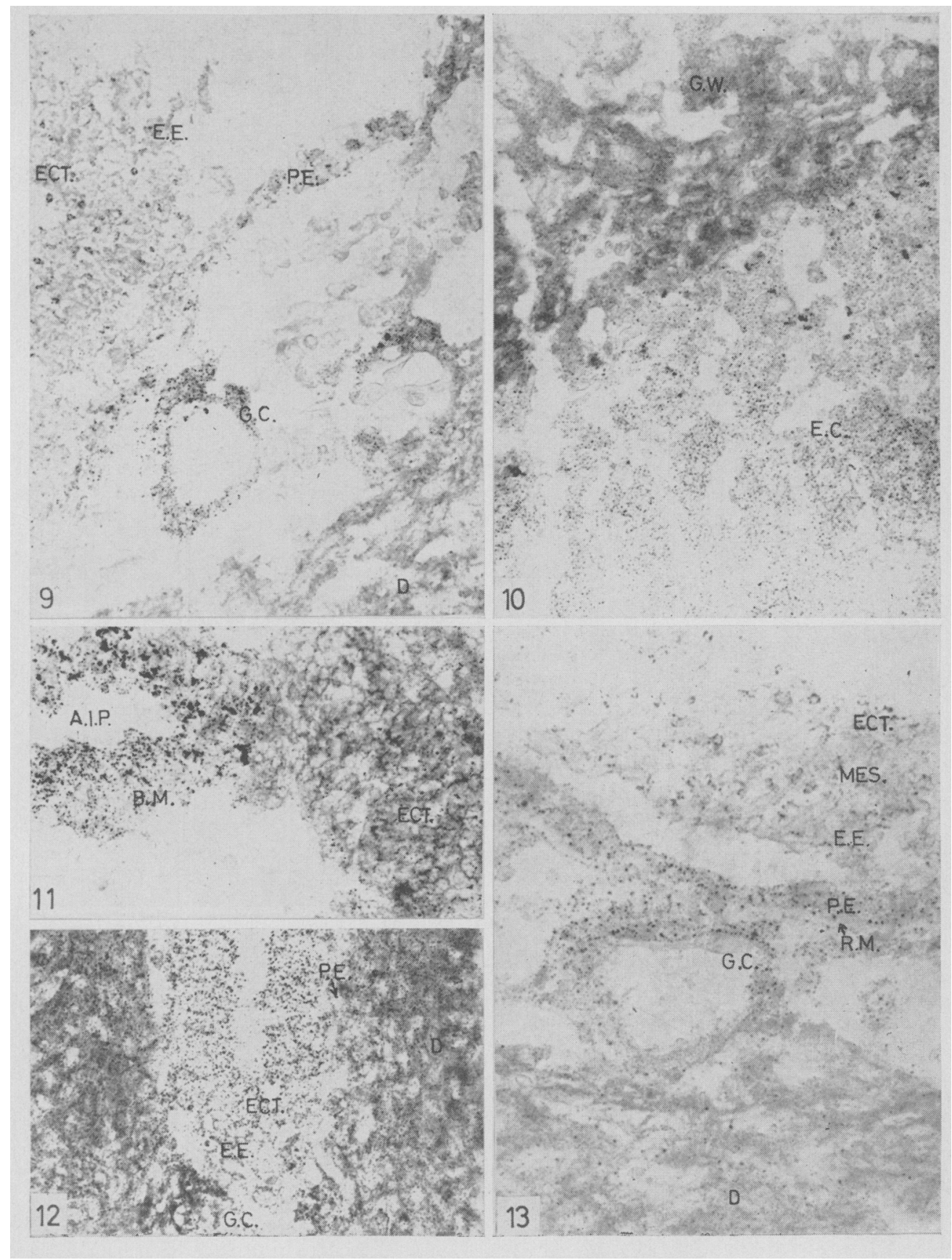

